\title{
SYNTHESIS AND CHARACTERIZATION OF POLYESTERS FROM RENEWABLE
} CARDOL

\author{
Y.M.M. Makame ${ }^{1 *}$, E.B. Mubofu ${ }^{1}$ and M.A. Kombo ${ }^{2}$ \\ ${ }^{1}$ Chemistry Department, University of Dar es Salaam, P.O. Box 35061, Dar es Salaam, Tanzania \\ ${ }^{2}$ Chemistry Department, State University of Zanzibar, P.O. Box 146 Zanzibar, Tanzania
}

(Received August 30, 2015; revised February 27, 2016)

\begin{abstract}
The preparation and thermal characteristics of new polyesters from cardol, a renewable monomer obtained as a by-product of the cashew industry, are reported. Cardol - a diol component of the natural product cashew nut shell liquid (CNSL) was isolated and reacted with adipoyl chloride and terephthaloyl chloride in a 1:1 molar ratio in hexane and toluene as solvents at $170{ }^{\circ} \mathrm{C}$ under nitrogen atmosphere. The cardol based polyesters [poly(cardyl adipate) and poly(cardyl terephthalate)] were produced in good yields of up to 63 and $54 \%$, respectively. The polymers were analysed by FT-IR for functional groups elucidation and by combined thermogravimetric analysis (TGA) and differential scanning calorimetry (DSC) for thermal stability. The cardolbased polyesters were thermally stable up to about $400{ }^{\circ} \mathrm{C}$. The thermal stability of poly(cardyl terephthalate) was higher than that of poly(cardyl adipate) under similar conditions. All prepared polyesters were insoluble in common laboratory solvents at room temperature.
\end{abstract}

KEY WORDS: Cashew nut shell liquid, Cardol, Polyesters, Renewable polymers

\section{INTRODUCTION}

Polymers dominate the chemical industry, making up around $80 \%$ of its output [1]. Globally, the annual polymer production is approximated at 250 million tonnes [2]. Most of these polymers are obtained from petrochemicals derived from fossil fuels. In recent years, the synthesis of polymers from renewable resources has attracted considerable attention by researchers [3, 4]. The shift to polymers from renewable resources is partly due to the escalating prices of petrochemicals and towering rate of depletion of crude oil reserves and environmental concerns about the use petroleum-based polymers. Renewable natural resources obtained from plants and animals in the form of cellulose, starch, sugar, lignin, oils and fatty acids provide a variety of naturally occurring materials from which a host of chemicals could be synthesized.

Cashew nut shell liquid (CNSL) which is obtained during the processing of cashew nuts, is a unique natural source for unsaturated long-chain phenols $[5,6]$. The annual world-wide production of CNSL is estimated at 300,000-360,000 tonnes and since the production of cashew nuts is rising up to 600,000 tonnes of CNSL per annum should be available reached in the near future [7]. CNSL is considered as one of the promising natural sources of phenolic compounds, useful as raw materials for organic syntheses [8] including polymer and nanomaterials production $[9,10]$. In addition to its low cost and abundant availability, consideration for CNSL industrial use is also due to its versatile chemical nature and low carbon footprint [11].

Depending on the mode of extraction from cashew nut shells, CNSL can be categorized into two types; solvent-extracted (natural) and thermal-extracted (technical) CNSL. The components of solvent-extracted CNSL include anacardic acid (60-65\%), cardol (15-20\%), cardanol (10\%) and traces of methyl cardol (Figure 1).

Thermal extraction of CNSL causes polymer formation and decarboxylation of anacardic acid to cardanol. As a result, the components of technical CNSL are mainly cardanol $(70-75 \%)$, cardol (15-20\%), polymeric materials (5-10\%) and traces of methyl cardol. Qualitative analyses

*Corresponding author. E-mail: yahya.makame@gmail.com 
of the CNSL components have established that the $\mathrm{C}_{15}$ side chain can either be a saturated alkyl group or an unsaturated alkenyl group [12].<smiles>[R]c1cc(O)cc(O)c1</smiles>

Anacardic acid cardol<smiles>Oc1cccc(I)c1</smiles>

cardanol

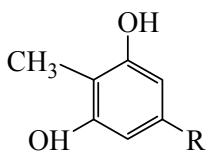

2-methyl cardol

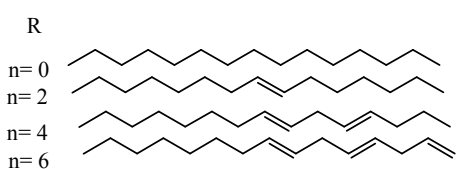

$\mathrm{n}=6$

$\mathrm{R}=\mathrm{C}_{15} \mathrm{H}_{31-\mathrm{n}}$ where $\mathrm{n}=0,2,4,6$

Figure 1. The structures of the major phenolic constituents of CNSL.

Considerable amount of research has been documented on the synthesis of polymeric materials from renewable CNSL and its components [13-23]. Varma and Sivaram [13] patented the preparation of a polycarbonate from a hydroxyalkyl phenol derived from cardanol. Chuayjuljit et al. [14] prepared cardanol-formaldehyde resins for the reinforcement of natural rubber while Bhunia et al. [15] documented the syntheses of polyether from cardanol. Bhunia et al. [16, 17], Mythili et al. [18] and Suresh and Kishanprasad [19] studied the synthesis, characteristics and processability of polyurethanes based on cardanol and the material revealed suitable mechanical and thermal properties. More et al. [20] prepared aromatic polyamides containing ether links and pendant pentadecyl chains using cardanol as the starting material for the monomer synthesis. The polyamides showed good thermal behaviour and good solubility in polar aprotic solvents. Philip et al. [21] reported on the preparation of molecularly imprinted polymers using anacardic acid while Bisanda and Ansell [22] studied the formulation and properties of sisal - CNSL reinforced composites. Cardanol has also been used for the preparation of specialty polymers such as liquid crystalline polyesters [23] and self-assembled organic nanotubes [24]. Resins derived from CNSL have been widely employed in the field of friction materials, surface coatings, adhesives, laminates, rubber compounding and for ion exchange and several other miscellaneous applications [25-28].

This work reports on the synthesis of polyesters using the renewable cardol. The interesting chemical characteristics of cardol originating from its aromatic hydroxyl system lead to a strategy of preparing the polyesters. Suitable reaction conditions for its polyesterification with diacid chlorides were sought to optimize the polymer yield. The prepared polyesters were characterized qualitatively and thermally using FT-IR and TGA/DSC techniques.

\section{EXPERIMENTAL}

\section{Materials and reagents}

Cashew nut shells were collected from Mtwara and the coastal region cashew nut processing factories, in Tanzania. The shells were processed to obtain cashew nut shell liquid (CNSL), from which cardol was isolated. All the chemicals and solvents used were of analytical grade and were used without further purification. The comonomers (terephthaloyl chloride and adipoyl chloride) were obtained from Sigma Aldrich, UK. Ammonia solution (25\%) was purchased from Scharlau Chemie SA while $\mathrm{KBr}$ and $\mathrm{N}, \mathrm{N}$-dimethylformamide were obtained from Chadwell Health, England. The other reagents and solvents were obtained from Sigma Aldrich and Carlo Erba-SDS. 


\section{Extraction of CNSL}

The procedure used by Paramashivappa et al. [6] for the extraction of CNSL was adopted. Sliced cashew nut shells ( $4000 \mathrm{~g}$ ) were soaked in petroleum ether for 3 days and CNSL leached out of the shells turning the colourless solvent into brown coloured liquid. The brown-coloured liquid was then filtered and the solvent was removed under reduced pressure using a rotary evaporator (LABOROTA 4001, Heidolph) at $40{ }^{\circ} \mathrm{C}$ to give $972.1 \mathrm{~g}$ of brown oily product (CNSL).

\section{Decarboxylation of CNSL}

The solvent extracted CNSL was heated in a furnace (Nabertherm Controller P 320) to a temperature of $200{ }^{\circ} \mathrm{C}$ for 4 hours to yield decarboxylated CNSL. Heating CNSL at $200{ }^{\circ} \mathrm{C}$ decaboxylates anacardic acid to cardanol.

\section{Separation of cardol and cardanol}

The decarboxylated CNSL contains two major components, namely, cardanol and cardol. These were separated according to the procedures described by Kumar et al. [5] and Parashivappa et al. [6] with some modification with respect to extraction time. In a typical experiment, $40.05 \mathrm{~g}$ of decarboxylated CNSL was dissolved in methanol $(128 \mathrm{~mL})$ and ammonium hydroxide $(25 \%$, $80 \mathrm{~mL})$ stirred for $210 \mathrm{~min}$. Cardanol was then extracted by adding n-hexane $(4 \times 80 \mathrm{~mL})$ where the organic layer was washed with $5 \% \mathrm{HCl}(40 \mathrm{~mL})$ followed by distilled water $(100 \mathrm{~mL})$. The organic layer was then dried over anhydrous sodium sulfate and concentrated under reduced pressure to give $25.038 \mathrm{~g}$ cardanol $(61.2 \%)$. The methanolic ammonia solution was extracted with ethyl acetate/hexane $(4: 1)(2 \times 80 \mathrm{~mL})$. The resulting organic layer was washed with $5 \%$ $\mathrm{HCl}(40 \mathrm{~mL})$ followed by distilled water $(100 \mathrm{~mL})$, dried over anhydrous sodium sulfate and concentrated to yield $16.2 \%$ (6.73 g) pure cardol. In this case, longer extraction times were found necessary for effective separation. The extracted cardanol and cardol were analyzed by IR spectrophotometry.

\section{Synthesis of cardol-adipoyl chloride polyesters}

In a typical experiment, a solution of cardol $(1.574 \mathrm{~g})$ in hexane $(5 \mathrm{~mL})$ was added to a solution of adipoyl chloride $(0.909 \mathrm{~g})$ in hexane $(5 \mathrm{~mL})$ in a three-necked reaction flask equipped with a magnetic stirrer, a condenser and a gas inlet. The flask was first evacuated and then filled with nitrogen gas and a slow stream of the gas was maintained to carry off the hydrogen chloride produced during the polymerization. The reaction mixture was heated in an oil bath at $170{ }^{\circ} \mathrm{C}$ for $8 \mathrm{~h}$ forming $1.562 \mathrm{~g}$ of a black brown soft solid polymer (Scheme 1a) which was then filtered and washed with acetone and later dried in an oven at $50{ }^{\circ} \mathrm{C}$ for further analysis.

\section{Synthesis of cardol - terephthaloyl chloride polyesters}

In a typical experiment, a solution of cardol $(1.016 \mathrm{~g})$ in toluene $(10 \mathrm{~mL})$ was added to a solution of terephthaloyl chloride $(0.651 \mathrm{~g})$ in toluene $(10 \mathrm{~mL})$ in a polymerization flask equipped with a magnetic stirrer, a condenser and a gas inlet and heated in an oil bath at $170{ }^{\circ} \mathrm{C}$. A hard, black solid polymeric material $(0.874 \mathrm{~g})$ was obtained after $8 \mathrm{~h}$ (Scheme $1 \mathrm{~b}$ ).

\section{Fourier Transform infrared spectroscopy (FT-IR) Analysis}

The analyses were carried out using a Bruker 2000 FTIR spectrophotometer at Chemistry Department, University of Dar es Salaam. The samples were dried overnight in a vacuum oven at $100{ }^{\circ} \mathrm{C}$ prior to analysis. Spectra were scanned in the mid-IR region $\left(4000\right.$ to $\left.600 \mathrm{~cm}^{-1}\right)$ at 4 $\mathrm{cm}^{-1}$ resolution with 5 scans. 


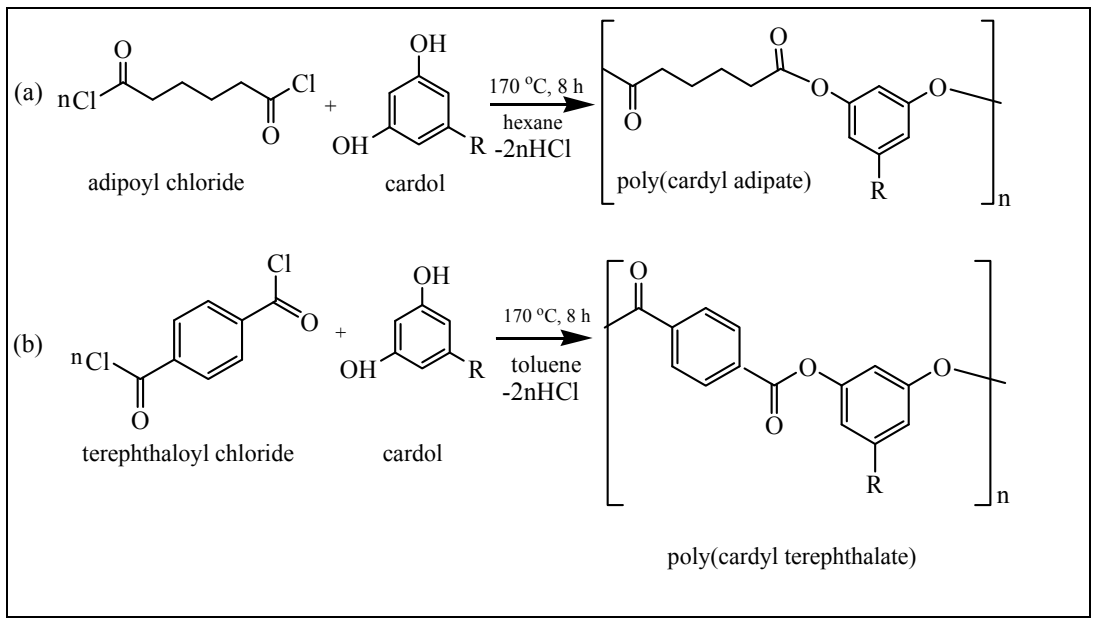

Scheme 1. Synthesis of cardol-based polyester using: (a) adipoyl chloride and (b) terephthaloyl chloride.

Thermogravimetry and differential scanning calorimetry

A combined TG-DSC Stanton Redcroft STA-780 thermo analyser from the Institute of Catalysis, School of Chemistry, University of Cardiff, was used. The analyses were conducted both in air ( $20 \%$ oxygen and $80 \%$ helium) and under inert atmosphere (100\% helium). The polymer samples were heated from 10 to $1000{ }^{\circ} \mathrm{C}$ oven temperature at a constant heating rate of $10{ }^{\circ} \mathrm{C} / \mathrm{min}$. Mass of samples ranged from 10.0 to $16.7 \mathrm{mg}$.

\section{Solubility of cardol-based polyesters}

The solubility of polyesters were tested in distilled water, dilute $\mathrm{HCl}$ solution $(0.1 \mathrm{M})$ and common organic solvents including DMSO, DMF, methanol and ethanol (polar) and acetone, dichloromethane, chloroform, diethyl ether, toluene, and hexane (nonpolar). Typically, $0.01 \mathrm{~g}$ of the polymer sample was placed in $5 \mathrm{~mL}$ of solvent at $30 \pm 2{ }^{\circ} \mathrm{C}$ overnight under agitation.

\section{RESULTS AND DISCUSSION}

\section{Extraction and decarboxylation of CNSL}

The percentages by weight of CNSL obtained in extraction experiments ranged between $20 \%$ and $24 \%$. These percentages are lower than those reported by other workers [28] (30-35\%) but higher than those reported by Philip et al. [21] (about 17\%). The variation in CNSL content is attributed to many factors including age of the cashew nut shells, soil type and the climate of where the cashew nuts were harvested.

The FT-IR spectra of the extracted natural CNSL and the decarboxylated CNSL are shown in Figure 2. The spectra indicate successful decarboxylation of CNSL as evidenced by complete disappearance of the strong absorption peak at $1724 \mathrm{~cm}^{-1}$, which confirms removal of $\mathrm{COOH}$ group of anacardic acid. The peak at $3600 \mathrm{~cm}^{-1}$ is due to $\mathrm{OH}$ group. 


\section{Separation of cardol and cardanol}

The major products of decarboxylated CNSL are cardol and cardanol. These were separated by using the procedure described by Kumar et al. [5] and Paramashivapa et al. [6] with modification with respect to equilibration time. In the separation of cardol from the decarboxylated CNSL, four experiments were performed in order to determine the effect of equilibration time on the efficiency of the separation. The stirring time was increased from 15 to $210 \mathrm{~min}$ in the experiments as shown in Table 1. The other steps were followed as described by the authors [5]. In this work longer equilibration times were found necessary for effective extraction of cardol from the decarboxylated CNSL. The limiting percentages of cardanol $(62.1 \%)$ and cardol $(16.0 \%)$ obtained from decarboxylated CNSL in this work were close to those reported by Kumar et al. [5] (i.e., $65 \%$ and 20\%, respectively).

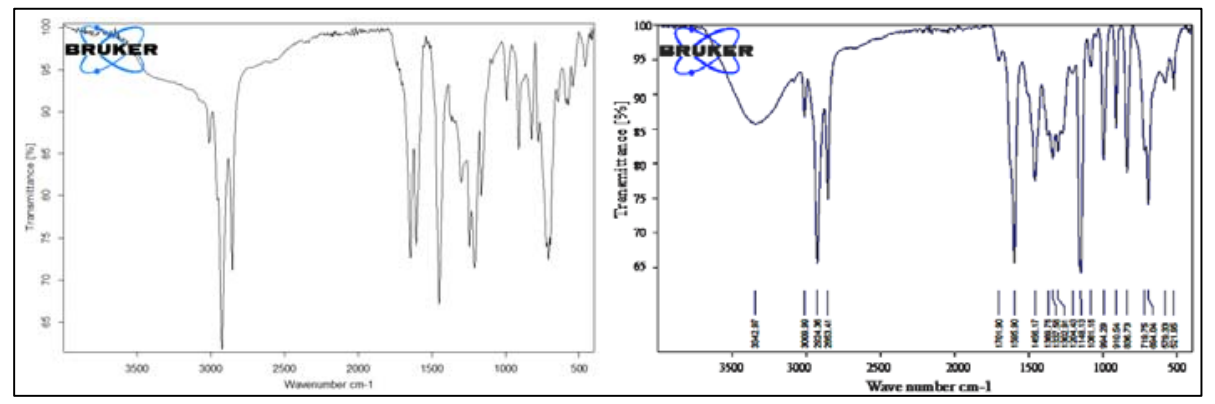

Figure 2. FT-IR spectra of natural CNSL (left) and decarboxylated CNSL at $200^{\circ} \mathrm{C}$ ) (right).

Table 1. Separation of cardanol and cardol from decarboxylated CNSL.

\begin{tabular}{|c|c|c|c|c|c|c|}
\hline $\begin{array}{c}\text { Exp. } \\
\text { No. }\end{array}$ & $\begin{array}{c}\text { Wt. of } \\
\text { D-CNSL }(\mathrm{g})\end{array}$ & $\begin{array}{c}\text { Time } \\
(\mathrm{min})\end{array}$ & $\begin{array}{c}\text { Wt. of } \\
\text { cardanol }(\mathrm{g})\end{array}$ & $\begin{array}{c}\% \text { of } \\
\text { cardanol }\end{array}$ & $\begin{array}{c}\text { Wt. of } \\
\text { cardol }(\mathrm{g})\end{array}$ & $\begin{array}{c}\% \text { of } \\
\text { cardol }\end{array}$ \\
\hline 1 & 20.057 & 15 & 16.299 & 81.3 & 0.758 & 3.8 \\
\hline 2 & 20.109 & 120 & 15.993 & 79.5 & 1.064 & 5.3 \\
\hline 3 & 40.086 & 210 & 24.89 & 62.1 & 6.411 & 16.0 \\
\hline
\end{tabular}

Synthesis of cardol-based polyesters

Cardol was polymerized with diacid chlorides (adipoyl and terephthaloyl chloride) under a number of experimental conditions to give the corresponding polyesters. The reaction conditions and polymer yields are shown in Table 2 . The reactions carried out at $120{ }^{\circ} \mathrm{C}$ resulted in low percentage polymer yields compared to those carried out at $170{ }^{\circ} \mathrm{C}$. The influence of temperature on the rate of polymerization as well as the molecular weight of the polymer formed is expected. Polyesterification reactions of diols with dicarboxylic acids or acid chlorides proceed by step-growth mechanism, thus long times are required for their completion and acquisition of higher molar mass polymers.

\section{Solubility properties of cardol-based polyesters}

The cardol-based polyesters were insoluble and sank in both polar solvents (water, dielectric constant, $\varepsilon=80$, DMSO, $\varepsilon=46.68$, DMF, $\varepsilon=36.71$, methanol, $\varepsilon=32.70$, ethanol, $\varepsilon=24.5$ and acetone, $\varepsilon=21$ ) and non-polar solvents (diethyl ether, $\varepsilon=4.33$, toluene, $\varepsilon=2.38$ and hexane, $\varepsilon$ $=1.89)$. In chlorinated hydrocarbons (dichloromethane $(\varepsilon=9.1)$ and chloroform $(\varepsilon=5)$ ), the 
polyesters were swollen and floated. In dilute aqueous $\mathrm{HCl}$, the polyesters were insoluble and floated on the solution. As is the case with most aromatic polyesters, the prepared polymers were insoluble in most common organic solvents at room temperature. The polymer shows the differences in solubility with those reported elsewhere [16]. Whereas these workers reported the synthesized polyesters to be soluble in most solvents, this study obtained polymers which were insoluble in all tested solvents. It must be pointed out that these polymers differ from reported by elsewhere in that while they employed cardanol as a monomer source this work used cardol as monomer source. This shows that the monomers have one $\mathrm{OH}$ functionality difference in the ring. The presence of an extra $\mathrm{OH}$ functionality could be responsible for further stabilization of the polymer and hence making it more difficult to solubilize by different solvents and hence the insolubility. The presence of pendant long alkyl chain on the polymer backbone originating from cardol is similar to that from cardanol and hence may not be responsible for the insolubility of the polymers. Due to solubility limitations, intrinsic viscosity of the polymers could not be determined.

Table 2. The experimental conditions and respective yields for the preparation of cardol-based polyesters.

\begin{tabular}{|c|c|c|c|c|c|c|c|c|}
\hline $\begin{array}{c}\text { Exp. } \\
\text { no. }\end{array}$ & $\begin{array}{c}\text { ADCl } \\
(\mathrm{g})\end{array}$ & $\begin{array}{c}\text { TPCl } \\
(\mathrm{g})\end{array}$ & $\begin{array}{c}\text { Cardol } \\
(\mathrm{g})\end{array}$ & $\begin{array}{c}\text { Solvent } \\
(10 \mathrm{~mL})\end{array}$ & $\begin{array}{c}\text { Temp } \\
{ }^{\circ} \mathrm{C}\end{array}$ & $\begin{array}{c}\text { Polymer } \\
(\mathrm{g})\end{array}$ & $\begin{array}{c}\text { Time } \\
(\mathrm{h})\end{array}$ & $\begin{array}{c}\text { Polymer } \\
\text { Yield }(\%)\end{array}$ \\
\hline 01 & 0.9669 & & 1.675 & Hexane & 120 & 0.576 & 7 & 21.8 \\
\hline 02 & & 1.1150 & 1.741 & Toluene & 120 & 0.582 & 7 & 20.4 \\
\hline 03 & 0.9086 & & 1.574 & Hexane & 170 & 1.562 & 8 & 62.9 \\
\hline 04 & 0.5957 & & 1.032 & Hexane & 170 & 0.972 & 8 & 58.6 \\
\hline 05 & & 0.6507 & 1.016 & Toluene & 170 & 0.874 & 8 & 52.4 \\
\hline 06 & 0.7632 & & 1.322 & Hexane & 170 & 1.021 & 8 & 49.0 \\
\hline 07 & & 0.9037 & 1.411 & Toluene & 170 & 1.254 & 8 & 54.2 \\
\hline
\end{tabular}

\section{FT-IR analysis of cardol-based polyesters}

FT-IR analysis was used to confirm the formation of ester links (COO- bonds) of the polyesters. The results show that indeed the ester linkage was successfully formed. This is evidenced by the $\mathrm{C}=\mathrm{O}$ peaks at 1761 and $1779 \mathrm{~cm}^{-1}$ in the spectra of poly(cardyl adipate) and poly(cardyl terephthalate), respectively (Figure 3 ). These peaks are in good agreement with those reported in literature by other workers [16]. The $\mathrm{C}=\mathrm{O}$ IR spectral peaks for the parent adipoyl chloride and terephthaloyl chloride monomers appeared at 1802 and $1787 \mathrm{~cm}^{-1}$, respectively, indicating a shift of the $\mathrm{C}=\mathrm{O}$ peaks in the polyesters due to the formation of ester bonds between cardol and the diacid chlorides.

\section{Thermogravimetric analysis of the polyesters}

The results of thermogravimetric analyses of the polyesters are presented in Figures 4-6. Figures 4a and 5a show the TGA curves and the respective temperature derivatives of the mass change (DTG) curves for cardol-adipoyl chloride polyesters and cardol-terephthaloyl chloride polyesters, respectively, in air, while Figure 6 represents the TGA curves and the respective DTG curves for the cardol-based polyesters in helium (inert) atmosphere.

All polymer samples exhibited similar behaviour under the test conditions. They showed a slow decrease in mass (up to about $5-10 \%$ mass loss) with temperature at low temperatures. This slow and small mass loss at lower temperatures could be attributed to the loss of the volatiles including monomeric and oligomeric species, solvents and adsorbed moisture from the samples. After about $5-10 \%$ mass loss, the TG curves showed a rapid decrease in mass with increase in temperature. This indicates the onset of initial decomposition or degradation. For these polymers, a more rapid decrease in mass of the samples with temperature is observed from 
about $400{ }^{\circ} \mathrm{C}$ indicating the start of vigorous decomposition. The TGA results show a very good correlation with those reported on similar types of polymers even though there is a slight difference on their thermal stability that is attributed to their structural differences [16].

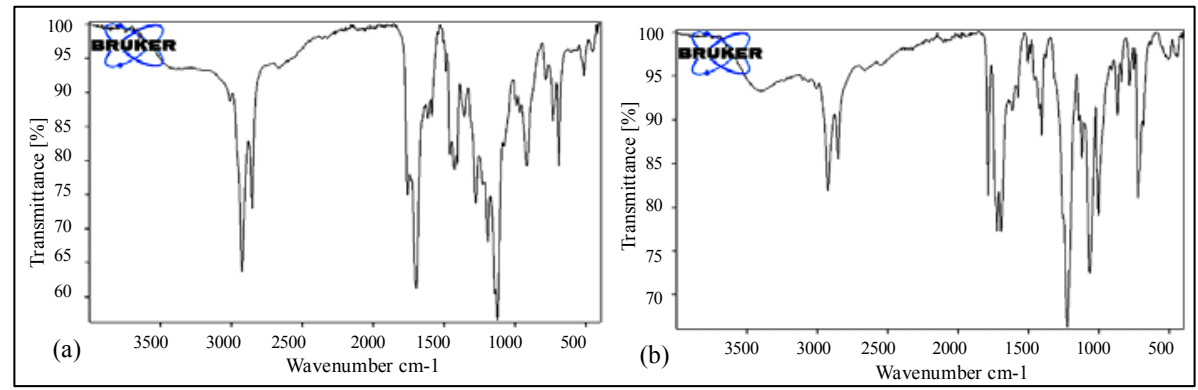

Figure 3. FTIR spectra of (a) cardol-adipoyl chloride polyester and (b) cardol-terephthaloyl chloride polyester.
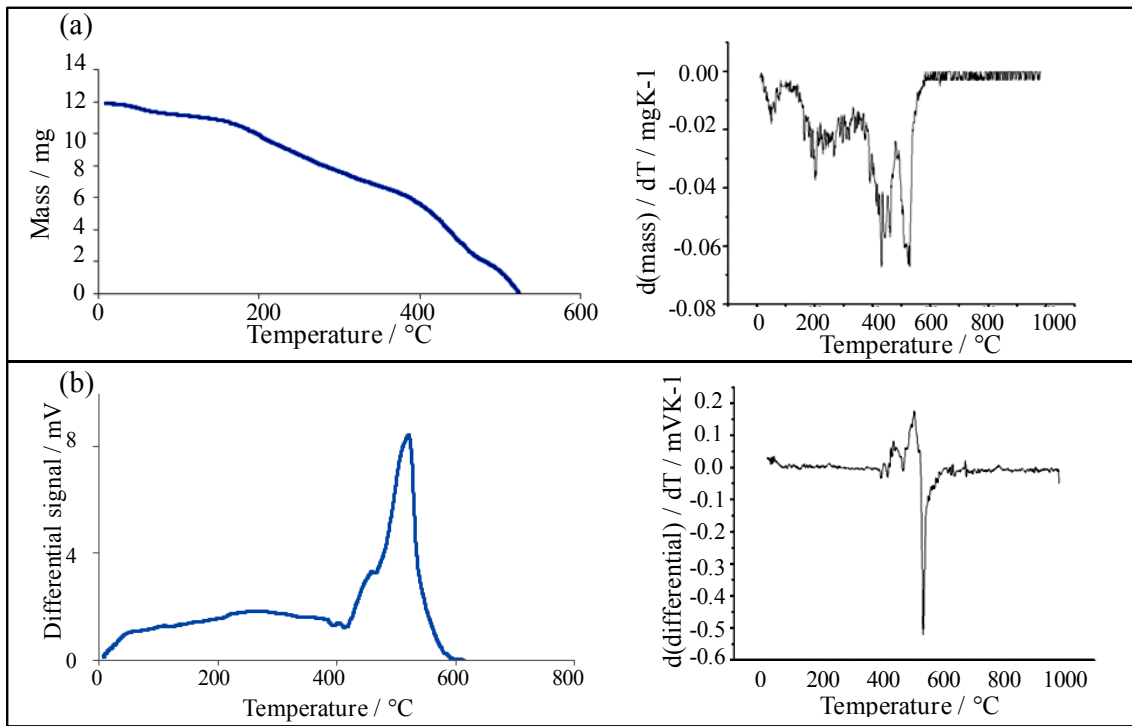

Figure 4. (a) TGA and derivative TGA curves and (b) DSC and derivative DSC curves for cardol-adipoyl chloride polyester in air at a heating rate of $10^{\circ} \mathrm{C} \mathrm{min}^{-1}$.

Under both test conditions, in air (Figures 4a and 5a) and in inert atmosphere (Figure 6), the DTG curves of the cardol-based polyesters exhibited two main peaks. The small peak indicating the loss of volatile materials appears at around $200-300{ }^{\circ} \mathrm{C}$ and the second peak, a relatively strong and sharp peak, representing the polymer decomposition appears at around $450{ }^{\circ} \mathrm{C}$. For the case of thermal treatment of the polyesters in inert atmosphere (Figure 6), a delay in weight loss was observed above $500{ }^{\circ} \mathrm{C}$ and $100 \%$ weight loss was approached at about $780{ }^{\circ} \mathrm{C}$ and 790 ${ }^{\circ} \mathrm{C}$ for cardol-adipoyl chloride polyester and cardol-terephthaloyl chloride polyester, respectively. These temperatures are higher than those achieved for the thermal treatment of the polymers in air, i.e. about $550{ }^{\circ} \mathrm{C}$. The delay in weight loss at higher temperatures observed 
during thermal treatment of the cardol-based polyesters in inert atmosphere could be attributed to the fact that in air, the measured weight losses are associated with both the decomposition and release of volatile components and combustion of solid by-products of pyrolysis whereas in inert atmosphere the combustion of solid by-products is suppressed.

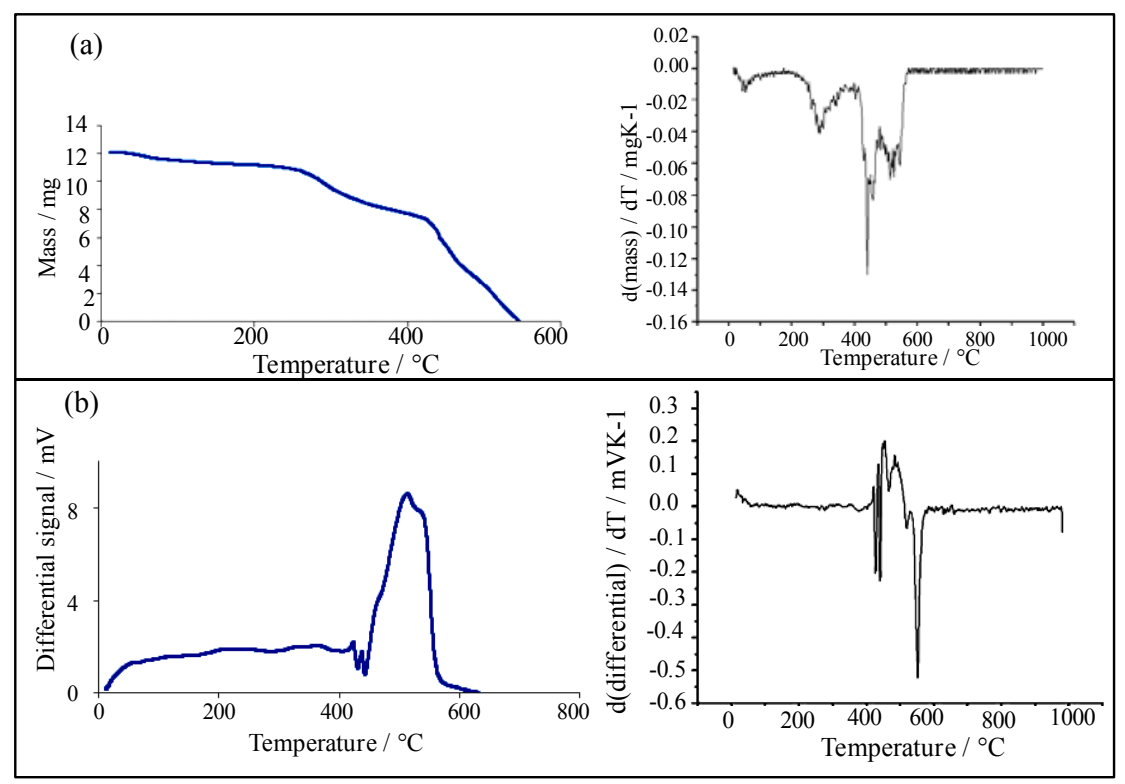

Figure 5. (a) TGA and derivative TGA curves and (b) DSC and derivative DSC curves for cardol-terephthaloyl chloride polyester in air at a heating rate of $10{ }^{\circ} \mathrm{C} \mathrm{min}^{-1}$.

Cardol-adipoyl chloride polyester (sample 03) and cardol-terephthaloyl chloride polyester (sample 05) differ slightly in their thermal stabilities as evidenced in Figures 4-6. The 10\% weight loss was attained at different temperatures for the two polymers, with cardolterephthaloyl chloride polymer at higher temperature $\left(\sim 250^{\circ} \mathrm{C}\right)$. The temperatures at which these losses are achieved are the same in both air and helium atmosphere. The difference in stability is due to their structural differences. The cardol-terephthaloyl chloride polyester required higher degradation temperature due to its more rigid structure compared to cardoladipoyl chloride polyester whose polymer chains are more flexible leading to softer polymer compared to the former.

\section{Differential scanning calorimetric (DSC) analysis of the polyesters}

The thermal transitions and thermal decomposition characteristics of the polymer samples were investigated using differential scanning calorimetry (DSC). Sample masses used in the DSC ranged from 11.4-14.3 $\mathrm{mg}$ and the DSC traces for cardol-based polyesters in air and their derivative curves are shown in Figures $4 \mathrm{~b}$ and $5 \mathrm{~b}$. The endothermic and exothermic peaks from the curves of derivative of DSC are tabulated (Table 3).

In the DSC curves of cardol-adipoyl chloride polyester and cardol-terephthaloyl chloride polyester (Figures $5 \mathrm{~b}$ and $6 \mathrm{~b}$, respectively) weak endothermic bands are observed at around 400 ${ }^{\circ} \mathrm{C}$ and strong exothermic peaks appear at around $500{ }^{\circ} \mathrm{C}$. The weak endothermic peaks can be attributed to the polymer melting while the strong exothermic peaks may be due to oxidative 
degradation of the polymer. As observed in the TG thermograms (Figures 4a, 5a and 6), the degradation process for the polyester is initiated with a small mass loss (about 10\%) of the sample weight followed by large mass loss with increasing temperature. At this latter stage, the sample releases energy as it degrades resulting in exothermic peaks as clearly seen in the DSC curves (Figures $4 \mathrm{~b}$ and $5 \mathrm{~b}$ ) for thermostability tests in air. The appearance of exothermic peaks at above $500{ }^{\circ} \mathrm{C}$ for poly (cardyl adipate) (sample 03) and poly(cardyl terephthalate) (sample 05) reflects the high thermal stabilities of these polymers.
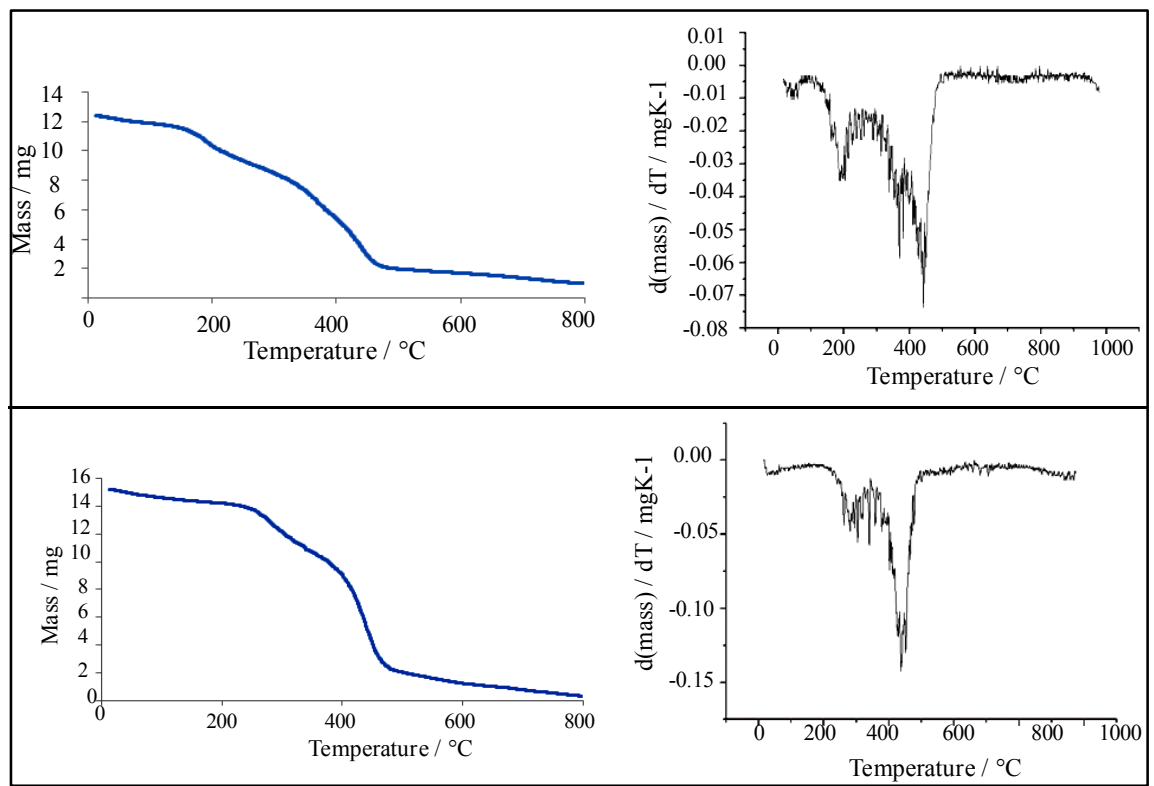

Figure 6. TGA curves and their respective DTG curves for cardol-adipoyl chloride polyester (top) and cardol-terephthaloyl chloride polyester (bottom) in helium atmosphere at a heating rate of $10^{\circ} \mathrm{C} \mathrm{min}^{-1}$.

Table 3. DSC peaks for different cardol-based polyesters (in air).

\begin{tabular}{|c|c|c|c|}
\hline Sample code & Polymer & Endothermic peaks $\left({ }^{\circ} \mathrm{C}\right)$ & Exothermic peaks $\left({ }^{\circ} \mathrm{C}\right)$ \\
\hline 01 & Cardol - ADCl & 420 and 460 & 530 \\
\hline 02 & Cardol - TPCl & 440 and 490 & 540 \\
\hline 03 & Cardol - ADCl & 400 and 460 & 530 \\
\hline 05 & Cardol - TPCl & 440 and 480 & 560 \\
\hline 06 & Cardol - ADCl & 460 & 520 \\
\hline
\end{tabular}

\section{CONCLUSION}

Cardol, a diol component of CNSL, is a promising renewable monomer resource for the preparation of aromatic polyesters. Cardol-based polyesters have successfully been prepared by polycondensation reaction of the monomer with diacid chlorides (adipoyl chloride and terephthaloyl chloride). The polymer yield seems to be affected by temperature and percentage yield of up to $63 \%$ was achieved at $170{ }^{\circ} \mathrm{C}$. The prepared polyesters were analysed by FT-IR for structural elucidation and by TGA and DSC for thermal stability. The cardol-based polyesters were thermally stable up to about $400{ }^{\circ} \mathrm{C}$. The cardol-terephthaloyl chloride polyesters appeared 
to show higher thermal stability than the cardol-adipoyl chloride polyesters. The polyesters were insoluble in common laboratory solvents.

\section{ACKNOWLEDGEMENTS}

Authors wish to thank Dr. Karen Wilson of the University of Cardiff for the TGA and DSC analyses and Mr. N. Komba for technical assistance with FTIR analysis. M.A. Kombo is grateful to the State University of Zanzibar (SUZA) for granting her study leave and to the World Bank, through SUZA, for financial support for her graduate studies at UDSM.

\section{REFERENCES}

1. European Renewable Resources and Materials Association, Renewable Polymers. Available

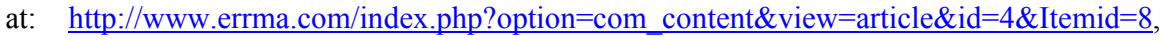
accessed 29 July 2012.

2. Chadha A. J. Commercial Biotechnol. 2010, 16, 159.

3. Tsujimoto, T.; Uyama, H.; Kobayashi, S. Biomacromolecules 2001, 2, 29.

4. Sporleder, T.L.; Goldsmith, P.D.; Cordier, J.; Godin, P. Int. Food Agribus. Man. Rev. 2011, 14,35 .

5. Kumar, P.P.; Paramashivappa, R.; Vithayathil, P.J.; Rao, P.V.; Rao, A.S. J. Agric. Food Chem. 2002, 50, 4705.

6. Paramashivappa, R.; Kumar, P.P.; Vithayathil, P.J.; Rao, A.S. J. Agric. Food Chem. 2001, 49, 2548.

7. Attanasi, O.A.; Berretta, S.; Fiani, C.; Filippone, P.; Mele, G.; Saladino, R. Tetrahedron 2006, 62, 6113 .

8. Rios, M.A.S.; Nascimento, T.L.; Santiago, S.N.; Mazzetto, S.E. Energy Fuels 2009, 23, 5432.

9.\# Lin, C.S.K.; Pfaltzgraff, L.A.; Herrero-Davila L.; Mubofu, E.B.; Abderrahim, S.; Clark, J.H.; Koutinas, A.A.; Kopsahelis, N.; Stamatelatou K.; Dickson, F.; Thankappan, S.; Mohamed, Z.; Brocklesby, R.; Luque, R. Energy Environ. Sci. 2013, 6, 426.

10. Mlowe, S.; Nejo, A.A.; Pullabhotla, V.S.R.; Mubofu, E.B.; Ngassapa, F.N.; O’Brien, P.; Revaprasadu, N. Mater. Sci. Semiconductor Process. 2013, 16, 263.

11. Rodrigues, F.H.A.; Feitosa, J.P.A.; Ricardo, N.M.P.S.; Franca, F.C.F.; Carioca, J.O.B. J. Braz. Chem. Soc. 2006, 17, 265.

12. Tyman, J.H.P. J. Chromatogr. A 1975, 111, 285.

13. Varma, A.J.; Sivaram, S. U.S. Patent 2002, 6, 451, 957 BI.

14 Chuayjuljit, S.; Rattanametangkool, P.; Potiyaraj, P. J. Appl. Polym. Sci. 2007, 104, 1997.

15. Bhunia, H.P.; Nando, G.B.; Basak, A.; Lenka, S.; Nayak, P.L. Eur.Polym. J. 1999, 35, 1713.

16. Bhunia, H.P.; Basak, A.; Chaki,T.K.; Nando,G.B. Eur.Polym. J. 2000, 36, 1157.

17. Bhunia, H.P.; Jana, R.N.; Basak, A.; Lenka, S.; Nando, G.B. J. Polym. Sci: Part A: Polym. Chem. 1998, 36, 391.

18. Mythili, C.V.; Retna, A.M.; Gopalakrishnan, S. Bull. Mater. Sci. 2004, 27, 235.

19. Suresh, K.I.; Kishanprasad, V.S. Ind. Eng. Chem. Res. 2005, 44, 4504.

20. More, A.S.; Pasale, S.K.; Wadgaonkar, P.P. Eur. Polym. J. 2010, 46, 557

21. Philip, J.Y.N.; Buchweishaija, J.; Mkayula, L.L.; Ye L. J. Agric. Food Chem. 2007, 55, 8870 .

22. Bisanda, E.T.N.; Ansell, M.P. J. Mater. Sci. 1992, 27, 1690.

23. Sanimathan, M.; Pillai, C.K.S. Polym. 2000, 41, 3103.

24. John, G.; Vemula, P.K. Soft Matter. 2006, 2, 909.

25. Lubi, M.C.; Thachill, E.B. Des. Monomers Polym. 2000, 3, 123.

26. Ilomo, O.O.; Makame, Y.M.M.; Mkayula, L.L. Bull. Chem. Soc. Ethiop. 2004, 18, 81.

27. Ilomo, O.O.; Makame, Y.M.M.; Mkayula, L.L. Bull. Chem. Soc. Ethiop. 2005, 19, 9.

28. Gedam, P.H.; Sampathkumaran, P.S. Prog. Org. Coat. 1986, 14, 115. 